\title{
Experimental Investigations on the Stir Casting of 6063 Aluminum Alloy for Automobile Applications
}

\author{
Tony Thomas.A*, Muthu Krishnan.A, Sre Nandha Guhan. K.S \\ Department of Mechatronics Engineering, Kongu Engineering College, Perundurai, Tamilnadu, India
}

Copyright $@ 2015$ Horizon Research Publishing All rights reserved.

\begin{abstract}
Composite materials play a major role in our automobile industries. The objective of the investigation is to fabricate a composite material which will be used as an alloy wheels in automobile vehicles. Existing alloy wheels used in vehicles nowadays includes aluminium alloys, aluminium nickel alloys, magnesium, steel, etc. These alloy wheels possess less fatigue, less thermal conductivity which in turn has less heat dissipation and also has less strength to withstand stress when it is allowed to impact with some load. In the proposed study, three metals which are combined to form a metal matrix composite that includes aluminium 6063, copper and gun metal. Aluminium is chosen because of its less weight. Copper is chosen because of its ability to dissipate heat quickly. Gun metal for its ability to with stand stress. The composite material is fabricated using Stir casting process which uses an induction furnace. The specimens are subjected to tensile test and hardness test using UTM (Universal Testing Machine) and Hardness tester respectively. From the result it is found that the tensile strength and hardness of the material increases with increasing in the addition of copper and gun metal.
\end{abstract}

Keywords Manufacturing, Stir Casting, Aluminium Matrix Composites, Copper, Gun Metal Alloy Wheel, UTM

\section{Introduction}

The particulate metal-matrix composites are extensively used for tribological applications due to excellent wear resistance especially during sliding as well as its ability to withstand high stress, low density and their ability to carry higher loads. The particulate reinforced metal matrix composite has been used to improve the strength of the alloy wheels used in automobile vehicles. Aluminium alloy with reinforcing particulates increased the hardness of the material. Severe problems were raised in order to dissipate the heat due to the friction between wheels. The study of hardness and tensile strength of composites at different stages has attracted attention in the past years. It has been found that oxidation layer formed during the time of heating dissipation. Hence temperature plays a major role in the metal matrix composites. Such interest on MMC by the researchers leads to the fabrication and testing of several composite materials with different properties.

\subsection{Literary Review}

Behera et al. (2011) studied about the aluminum alloy i.e. LM6 based composites reinforced with different weight fraction of $\mathrm{SiC}$ particles produced by stir cast technique and the effect of reinforced ratios on the forgeability and the machinability

Ceschini (2006) shows that the tensile and fatigue properties of the composite materials varies based on the amount of the additives added to the composite material.

Chaiyacote et al. (2010) employed a method of preparation of alumina and tungsten carbide-cobalt composite material for cutting tools and found that $\mathrm{Al}_{2} \mathrm{O}_{3} / \mathrm{WC}-\mathrm{Co}$ composite material provides high hardness fracture, toughness as well as strength.

Jiang et al. (2012) compared the mechanical properties and microstructure of the AZ91D magnesium alloy used in motorcycle wheels formed by double control forming by DCF machine.

Popoola et al. (2011) found that the intermetallic matrix composites formed by means of X-ray diffraction.

Salzar (1999) examined the Hybrid composite comprised of low- alloy gun steel on the inner region of the gun barrel and circumferentially wound $\mathrm{SiC} / \mathrm{Ti}-24 \mathrm{Al}-11 \mathrm{Nb}$ on the outer region can still exhibit the same compressive residual stress Singla et al. (2009) performed an field work on aluminum based silicon carbide development using stir casting technique changes with increase in weight percentage of $\mathrm{SiC}$.

\section{Chemical Composition of the Selected Materials}

The chemical composition of the material used, by means of its weight composition are as follows:

- Aluminium 6063 alloy - Silicon - $0.2 \%$ to $0.6 \%$ by weight, Iron - $0.35 \%$, Copper - $0.10 \%$, Manganese - 
$0.10 \%$, Magnesium - $0.45 \%$ to $0.9 \%$, Chromium -

$0.10 \%$, Zinc $-0.10 \%$, Titanium $-0.10 \%$, Other elements no more than $0.05 \%$ each, $0.15 \%$ total and Remaining Aluminium

- Gunmetal alloy - Copper (88\%), Tin (10\%), Zinc (2\%)

- Copper (100\%)

\section{Pattern Making (Sand Casting)}

Sand casting is a process of pattern making. In order to carry out the tensile strength and hardness test the material to be fabricated, must follow the ASTM standards. So based on the ASTM dimensions the pattern is made. The following figure 1 and figure 2 shows the pattern making from sand casting.

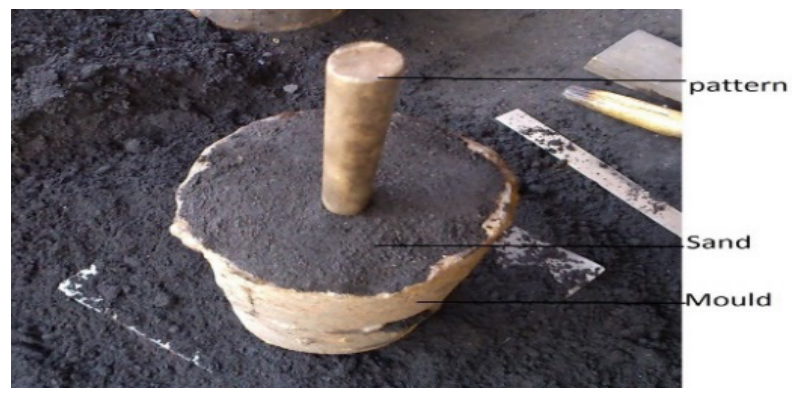

Figure 1. Pattern making for bar

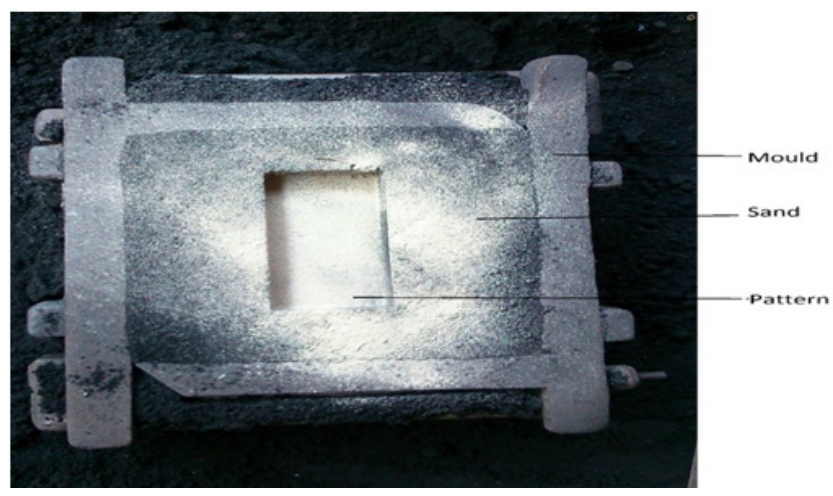

Figure 2. Pattern making for rod

\section{Material Fabrications}

Based on the ASTM standards the size of the work piece to be fabricated is set as $100 \times 25 \times 10$ (bar) for hardness calculation and $400 \times 10$ (rod) for tensile strength calculation.

\section{Experimental Procedure}

The experimental setup consists of covered electric furnace which is used to melt the Aluminium 6063 T6 Ingots along with copper borings and gun metal. The temperature of the electric furnace is monitored with the help of a thermocouple. Feeder and stirrer are attached with a rod in which the stirrer is connected to an electric motor as shown in the figure 3.First the aluminium is preheated and allowed to melt in the crucible temperature of $900^{\circ} \mathrm{C}$. The temperature is maintained at $900^{\circ} \mathrm{C}$ for about two and half hour, the time taken by the aluminium to melt. After this the copper borings are added and the temperature is raised to $1000^{\circ} \mathrm{C}$ and $1200^{\circ} \mathrm{C}$ after sometime. This mixture of aluminium and copper is stirred using a stirrer made up of stainless steel, whose melting point is $1510^{\circ} \mathrm{C}$. Then after sometime Gun metal is added with the same temperature of $1200^{\circ} \mathrm{C}$ and the whole mixture is stirred for about half an hour. After 10 minutes the stirrer is removed and molten MMC is poured into the mould. The mould is then allowed to cool for about 10 minutes after that the work piece is taken from the mould by breaking it.

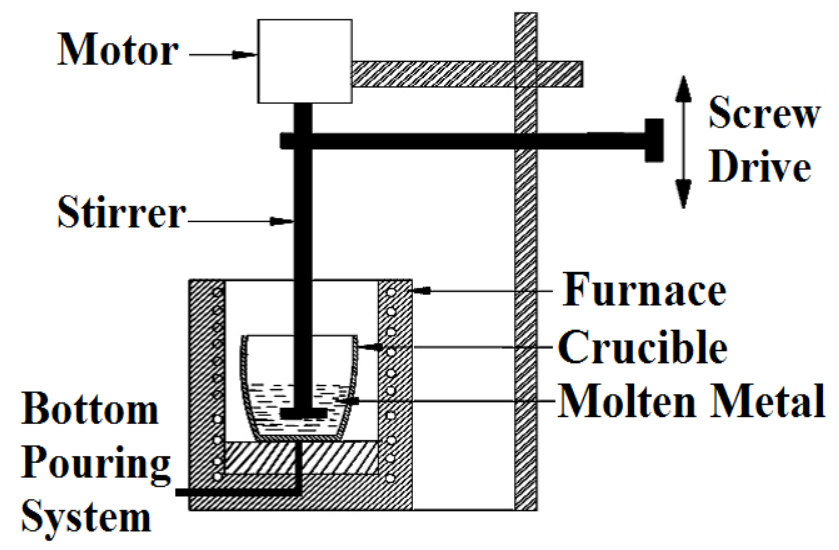

Figure 3. Stir casting apparatus

\section{Testing}

The testing of the composite materials includes

- Tensile strength testing

- Hardness testing

\subsection{Tensile Strength Testing}

Table 2. Tensile Strength of the Specimens

\begin{tabular}{|c|c|}
\hline Specimen Details & $\begin{array}{c}\text { Tensile strength } \\
\left(\mathrm{N} / \mathrm{mm}^{2}\right)\end{array}$ \\
\hline Specimen 1 (Al-250) & 150 \\
\hline Specimen 2 (Al-245, Cu-5) & 100 \\
\hline Specimen 3 (Al-242, Cu-5, and Gm-3) & 150 \\
\hline Specimen 4 (Al-240, Cu-5, and Gm-5) & 200 \\
\hline Specimen 5 (Al-240, Cu-7, and Gm-3) & 120 \\
\hline Specimen 6 (Al-235, Cu-10, and Gm-5) & 160 \\
\hline
\end{tabular}

The load applied to the specimen is fixed as $1200 \mathrm{~N}$, by applying this constant load the number of divisions the specimen will withstand can be calculated using the Universal Testing Machine. 


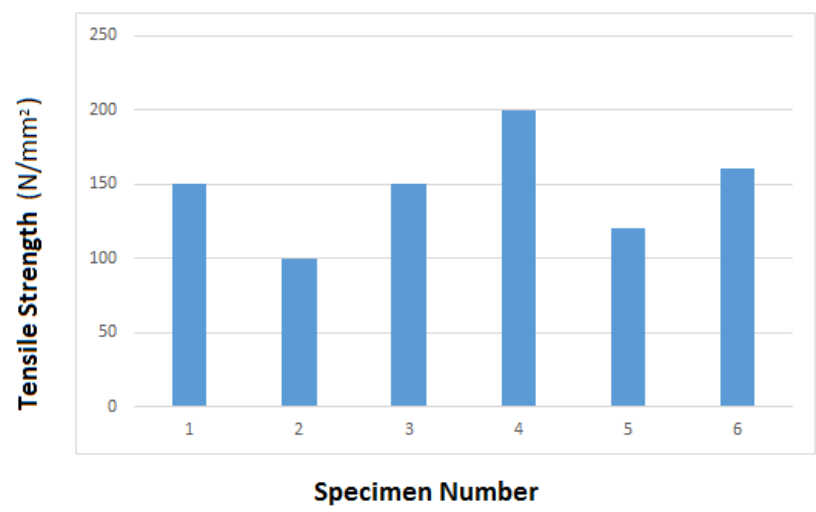

Figure 4. Tensile strength bar chart comparison

The bar chart shown in the figure 4 shows the tensile strength of the specimens. From the chart it is clear that the tensile strength of the specimen 4 is found to be high but it lacks its conductivity nature because of the absence of copper. In specimen 6 the strength also increases as well as the conductivity may also increases because of copper added to it. Hence it is recommended to implement in alloys wheels.

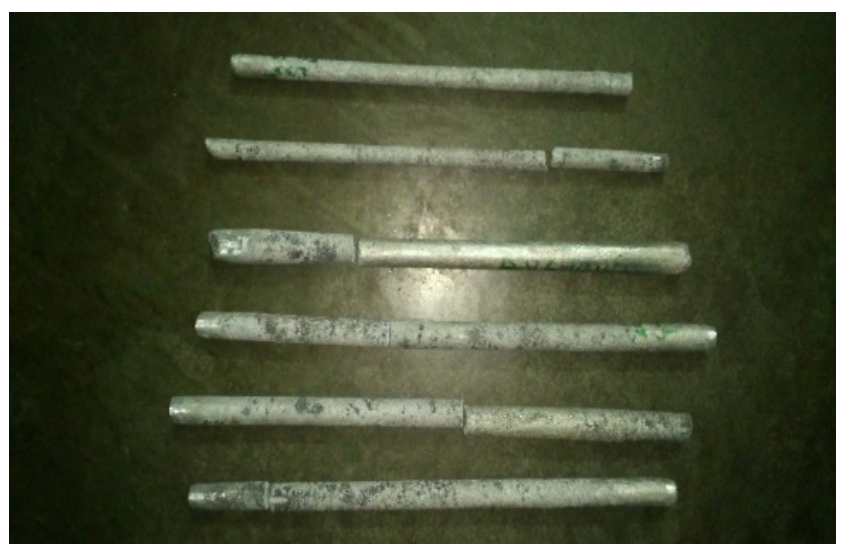

Figure 5. Fabricated material (rod)

\subsection{Hardness Testing}

The hardness of the material is calculated by means of Brinell hardness test whereas it mostly used for metals and alloys. The test is achieved by applying a known load to the surface of the tested material through a hardened steel ball of known diameter. The diameter of the resulting permanent impression in the tested metal is measured.

Table 3. Brinell hardness number

\begin{tabular}{|c|c|}
\hline Specimen Details & Brinell hardness number \\
\hline Specimen 1 (Al-250) & 140.12 \\
\hline Specimen 2 (Al-245, Cu-5) & 130.96 \\
\hline Specimen 3 (Al-242, Cu-5, and Gm-3) & 147.58 \\
\hline Specimen 4 (Al-240, Cu-5, and Gm-5) & 167.28 \\
\hline Specimen 5 (Al-240, Cu-7, and Gm-3) & 140.12 \\
\hline Specimen 6 (Al-235, Cu-10, and Gm-5) & 155.19 \\
\hline
\end{tabular}

The bar chart shown in the figure 6 shows the hardness of the specimens. From the chart it is clear that the hardness of the specimen 4 is found to be high but it lacks its conductivity nature because of the absence of copper. In specimen 6 the hardness also increases as well as the conductivity may also increases because of copper added to it. Hence it is recommended to implement in alloys wheels.

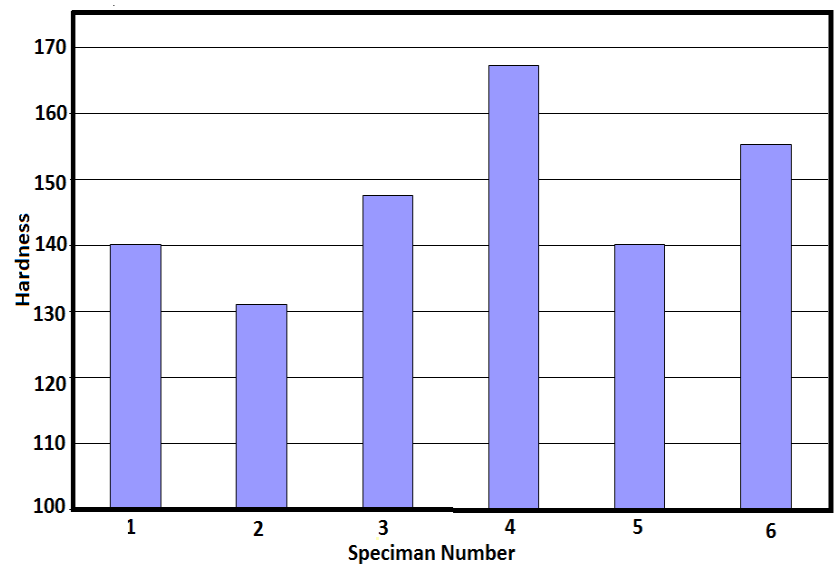

Figure 6. Hardness bar chart comparison

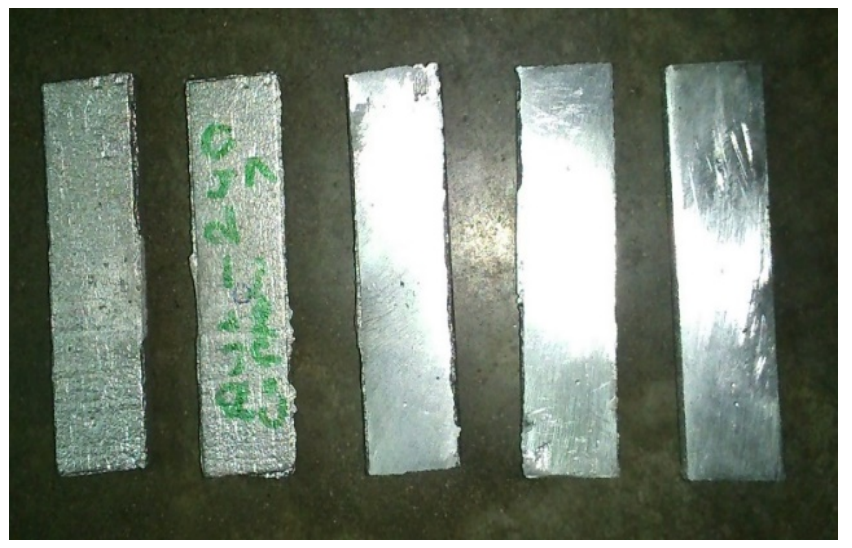

Figure 7. Fabricated material (bar)

\section{Result}

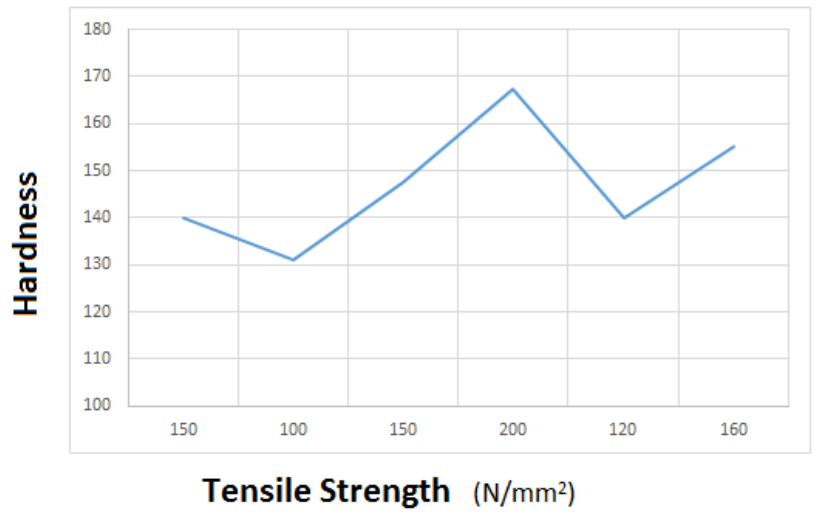

Figure 8. Tensile strength (N) vs Hardness 
From the figure 7 it is found that the tensile strength and hardness of the material increases linearly for each specimen, shows that the material with aluminium, copper and gun metal shows the highest tensile and hardness.

Following results are interpreted, from the data obtained from the testing:

- The tensile strength of the material increases by $25 \%$ from aluminium to composite material of aluminium + copper + gun metal.

- The hardness of the material increases by $16 \%$ from aluminium to the composite material of aluminium + copper + gun metal.

\section{Conclusions}

Aluminium matrix composites have been successfully fabricated with fairly uniform distribution of copper and gun metal. Dispersion of copper and gun metal particles in aluminium matrix improves the hardness of the matrix material and also the tensile strength of the composite. The effect is the increase in interfacial area between aluminium matrix and gun metal particles leading to the increase in strength appreciably. Coefficient of friction decreases as the load increases. Addition of copper with aluminium increases the thermal conductivity, in turn helps in dissipation of heat from it. Thus it is proved that, among all other composite materials, the combination of Aluminium, Copper and Gun metal, provide increased tensile strength and improved thermal conductivity. Also the present experimental work suggests the cheapest method for fabricating alloy wheels for automobiles.

\section{REFERENCES}

[1] Assan, A. M., Alrashdan, A., Hayajneh, M. T., \&Mayyas, A. T. (2009). Prediction of density, porosity and hardness in aluminum-copper-based composite materials using artificial neural network. Journal of materials processing technology, 209(2), 894-899

[2] Behera, R., Das, S., Chatterjee, D., \&Sutradhar, G. (2011). Forgeability and Machinability of Stir Cast Aluminum Alloy Metal Matrix Composites. Journal of Minerals and Materials Characterization and Engineering, 10, 923 -927.

[3] Ceschini, L. (2006). Tensile and fatigue properties of the Composites Science and Technology. 66, 333-342.

[4] Chaiyacote, V., Buggakupta, W., \&Chuankrerkkul, N. (2010). Mechanical Properties and Microstructure of Al2O3/WC-Co Composites. Journal of Metals, Materials and Minerals, 20(3), 5-8.

[5] Jiang, J., Wang, Y., Chen, G., Liu, J., Li, Y., \&Luo, S. (2012). Comparison of mechanical properties and microstructure of AZ91D alloy motorcycle wheels formed by die casting and double control forming. Materials \& Design, 40, 541-549.

[6] Popoola, A. P. I., Pityana, S. L., Fedotova, T., \&Popoola, O. M. (2011). Quantitative study of the hardness property of laser surface alloyed aluminium AA1200. Journal of the South African Institute of Mining and Metallurgy, 111(5), 335-347.

[7] Salzar, R. S. (1999). Influence of autofrettage on metal matrix composite reinforced gun barrels. Composites Part B: Engineering, 30(8), 841-847.

[8] Singla, M., Dwivedi, D. D., Singh, L., \& Chawla, V. (2009). Development of aluminium based silicon carbide particulate metal matrix composite. Journal of Minerals and Materials Characterization and Engineering, 8, 455-465. 